\title{
DEVELOPMENT OF A NEW BURNER DEVICE BASED ON INJECTION-RADIATION METHOD FOR GAS FUEL COMBUSTION
}

\author{
A A Sinitsyn ${ }^{1, *}, O Y$ Nikiforov $^{1}$, Timur Akhmetov $^{2}$ and $D F$ Karpov $^{1}$ \\ ${ }^{1}$ Department of Heat and Gas and Water Supply, Vologda State University, Lenina str. 15, 160000, Russia \\ ${ }^{2}$ Kazan State Power Engineering University, Kazan, Russia
}

\begin{abstract}
This paper presents the results of designing a promising burner device that combines injection and radiation methods for gaseous fuel combustion. Infrared radiation from the heated surface of nozzle of radiation burner provides intensive heat transfer in furnaces and boilers, specifies their high efficiency at low flue gas temperatures, and very low NOx emissions. Effective gas combustion is facilitated by additional heating of the initial fuel mixture during filtration through the hot walls of porous nozzle. The new design of radiation burner has high performance characteristics, provides effective combustion of gaseous fuel up to $99 \%$ and meets high environmental standards and requirements.
\end{abstract}

\section{Introduction}

Energy industry is one of the leading branches of human activity. Heat and light in houses, traffic flows and industry require a huge amount of energy. Currently, these needs are borne by mineral resources such as coal, natural gas, oil, reserves of which are limited and there are a number of works considering ways to increase the efficiency of their usage or other approaches for obtaining energy [1-5].

Today, the most economical and efficient type of fuel is natural gas. This is explained by its high calorific value, good transportability, minimum amount of harmful substances from combustion products, etc. The "blue fuel" releases heat during its burning in a mixture with an oxidizing agent. For this, various gas burner devices are used. In this connection promising is the development and construction of new devices and systems providing the most complete combustion of fuel, as well as reducing emissions of harmful substances into the air.

The aim of this work is to develop a new energyefficient burner device with high performance characteristics, which meets environmental standards and requirements.

To achieve this goal, the following tasks were set:

- To conduct a review of currently used gas burner devices, to identify their main advantages and disadvantages;

- To develop a concept of a new burner device which doesn't have the identified disadvantages;

- To develop a device model;

- To perform computational and experimental studies;

- To give a technical assessment of the possible use of such devices;
- To draw conclusions on the performed work

Many companies carried out research in the field of low-power burner development and fuel combustion, in particular NPO CKTI OJSC, ORGRES Firm, VNIIpromgaz, MosgazNIIproekt, Tomsk Polytechnic University. A substantial contribution to the development of such burner devices was made by R.B. Akhmedov, O.N. Bruhanov, A.S. Isserlin, M.I. Pevzner, R.I. Esterkin, V.A. Khristich, I.Ya. Seagal, K.F. Rider and others. The conducted research work allowed creating different types of burner devices, such as diffusion, blasting, injection, rotary, etc., which have received wide industrial implementation. In recent years, the main attention of international researcher groups has been directed to studying the processes of gasification and intensification of fuel combustion processes. For example, the works of S.E. Najim, A.C. Styles, N. Syred [6] and Nanjia Yu, Bo Zhao, Gonghan Li, Jue Wang [7] present experimental and simulation studies of fuel combustion intensification due to high-tech mixture formation.

Earlier studies were carried out on the efficiency of gaseous fuel burning under intensification by creating pulsations and exposure to magnetic field [8-10]. It is worth to note the developments $[11,12]$, in which new methods for increasing the efficiency of fuel combustion and monitoring the pressure of the gas-air medium in fire equipment for various purposes are proposed.

At present burners are of various designs ensuring their vast usage and stable demand in the market. The performed patent studies required for development of new products [13-15] allowed us to analyze the existing technical solutions which received protection documents. A review of the selected patents for gas burner devices showed that they all have a number of disadvantages and the area of further research is free enough for the

\footnotetext{
Corresponding author: sinitsyn.science@ mail.ru
} 
Table 1. Comparative characterization of burners available in the market.

\begin{tabular}{|l|c|c|c|}
\hline \multicolumn{1}{|c|}{ Parameter } & Ballu BIGH-4 & Komfort Prometei & Bartolini Primavera I \\
\hline Maximum thermal power, kW & 4.5 & 2.3 & 4.2 \\
\hline Fuel type & propane/butane & propane/ natural butane & propane/butane \\
\hline Nominal gas consumption, g/hour & $207 / 327$ & 180 & $100-300$ \\
\hline $\begin{array}{l}\text { Dimensions of device (WxHxD), } \\
\text { mm }\end{array}$ & $338 \times 372 \times 278$ & $255 \times 150 \times 100$ & $780 \times 430 \times 420$ \\
\hline Weight & 2.3 & 1.4 & 13 \\
\hline Producing country & China & Russia & Italy \\
\hline
\end{tabular}

introduction of new designs. The objective of this study is to reduce the loss of thermal energy, to increase the resistance of porous nozzle to thermal loads, to achieve more complete combustion of fuel, to increase the reliability of combustion by reducing the thermal conductivity of nozzle.

A comparison of devices currently available on the heating equipment market, which are analogues by the principle of operation, is given in table 1.

The review of gas burners showed that they have a maximum thermal power of 2.3-4.5 $\mathrm{kW}$, while the nominal flow velocity can vary from 100 to $327 \mathrm{~g} /$ hour. All of them are quite compact, safe and easy to transport. They can operate both on liquefied and natural gas. They are mainly used for room heating, but all have German ceramic panels as a heating element.

A patent and literature search showed that there are analogues of burner devices based on the injectionradiation method for burning gaseous fuels, but they all have a number of disadvantages.

\section{Concept of a new burner device}

The purpose of this study is achieved by combining the injection and radiation components in the burner. The burner body has a standard version of an injection burner with a superstructure of integrated nozzle for burning and afterburning of fuel. The new device belongs to the thermal power systems, namely to gas flameless injection burners with refractory nozzles.

A feature of this device is a stacked nozzle made of tiles of heat-resistant ceramics. A combustion stabilizer is placed above the nozzle, which is made as a heatresistant grating that acts as gas afterburner, flame stabilizer and additional emitter. These features result in a more complete combustion of fuel due to a combination of methods for burning and afterburning of the fuel-air mixture.

A sectional view of a burner device based on an injection-radiation method for burning gaseous fuel is presented in fig. 1 .

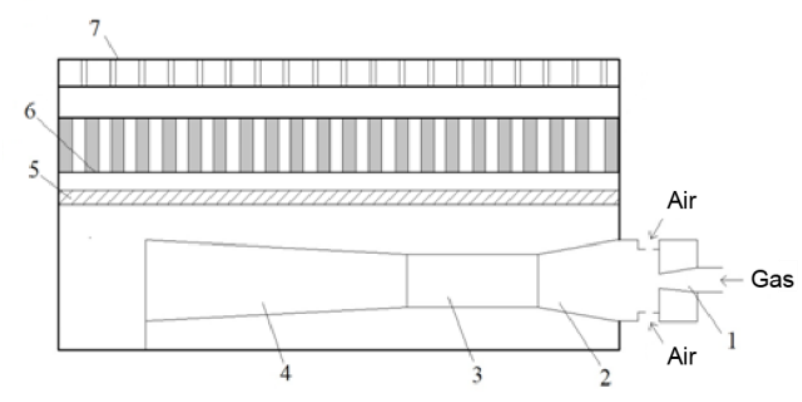

Fig. 1. Sectional view of a burner device based on injectionradiation method for burning gaseous fuels.

The operation principle of the device is as follows: gaseous fuel is supplied through the snout (1), while injecting the air necessary for combustion. In a mixer consisting of confuser (2), nose section (3), diffuser (4), fuel is mixed with air. The resulting air-fuel mixture through the distribution grid (5) enters the nozzle (6) and burns in the boundary areas of nozzle. The combustion stabilizer (7) contributes to fuel afterburning, the hot surface of nozzle and the combustion stabilizer create radiation flow and heat the surrounding objects. The nozzle, made of tiles of heat-resistant ceramics, provides optimal combustion conditions, has low thermal conductivity, prevents the spread of flame under the nozzle, even with wide limits of power control of the burner device.

The theoretical calculation of gas burners is very complicated and time-consuming, since it is associated with complex calculations of the processes of mixing, combustion and heat transfer, which should provide both high efficiency of gas fuel combustion, and the lowest possible concentration of harmful components in the combustion products. Due to the complexity of calculations, it is necessary to use a number of approximation data obtained from practice or particular experiments. This is demonstrated in $[16,17]$, where the main stages of design and simulation of such devices were shown.

The design calculation of burner device was reduced to determination of dimensions of the main elements of gas burner: snout, nose section, mixer, confuser, diffuser and nozzle [18]. The design scheme is shown in fig. 2. 


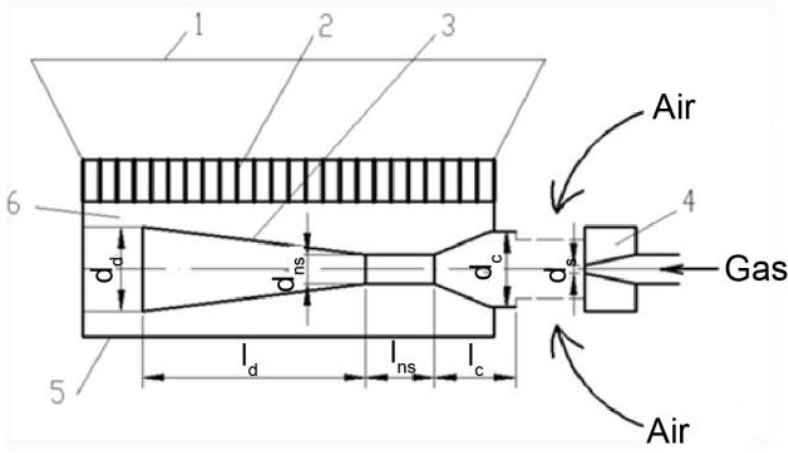

Fig. 2. Design scheme of an injection gas burner with a ceramic nozzle.

Fig. 2 conventionally shows the following elements: 1-reflector; 2-ceramic nozzle with holes; 3-injection mixer; 4-gas snout; 5-body; 6-channel head.

It should be noted that the ranges of stable operation of injection burners are limited by the possibility of flame lifting and flashback. Therefore, the calculation should be based on the velocity of gas-air mixture flow through the nozzle $(0.11-0.16 \mathrm{~m} / \mathrm{s})$ and the size of fire holes in tiles (1.5-2 mm). So, the designed burner device has thermal load limits from 2.53 to $3.96 \mathrm{~kW}$. The source data and the calculation results are presented in tables 2 and 3, respectively.

Table 2. The source data for design.

\begin{tabular}{|c|c|c|}
\hline Name & \multicolumn{2}{|c|}{ Value } \\
\hline Thermal load $Q_{\mathrm{g}}, \mathrm{W}$ & 2530 & 3960 \\
\hline $\begin{array}{l}\text { Net volumetric calorific value } Q_{\mathrm{n}} \text {, } \\
\mathrm{kJ} / \mathrm{m}^{3}\end{array}$ & \multicolumn{2}{|c|}{35590} \\
\hline Gas density $\rho_{0}, \mathrm{~kg} / \mathrm{m}^{3}$ & \multicolumn{2}{|c|}{0.74} \\
\hline Gas pressure before snout $\mathrm{P}_{\mathrm{g}}, \mathrm{Pa}$ & \multicolumn{2}{|c|}{3000} \\
\hline $\begin{array}{l}\text { Theoretically required amount of air } \\
V_{\mathrm{g}}, \mathrm{m}^{3} / \mathrm{m}^{3}\end{array}$ & \multicolumn{2}{|c|}{9.015} \\
\hline Excess air ratio, $\alpha$ & \multicolumn{2}{|c|}{1.05} \\
\hline
\end{tabular}

\section{Results}

The main design outputs are presented in table 3 [18] for two load parameters.
Table 3. Calculated data and design outputs.

\begin{tabular}{|l|c|c|}
\hline \multicolumn{1}{|c|}{ Name } & \multicolumn{2}{c|}{ Value } \\
\hline Total heat load $\mathrm{Qg}_{\mathrm{g}}, \mathrm{W}$ & 2530.00 & 3960.00 \\
\hline $\begin{array}{l}\text { Gas consumption for a burner, } \\
\mathrm{V}_{\mathrm{g}, \mathrm{m}^{3} / \mathrm{h}}\end{array}$ & 0.26 & 0.33 \\
\hline $\begin{array}{l}\text { Diameter of snout cross section } \\
\mathrm{d}_{\mathrm{s}}, \mathrm{mm}\end{array}$ & 1.03 & 1.29 \\
\hline $\begin{array}{l}\text { Diameter of nose section of } \\
\text { injection mixer } \mathrm{d}_{\mathrm{ns}}, \mathrm{mm}\end{array}$ & 12.37 & 15.48 \\
\hline Diameter of confuser $\mathrm{d}_{\mathrm{c}}, \mathrm{mm}$ & 18.56 & 23.22 \\
\hline Diameter of diffusor $\mathrm{d}_{\mathrm{d}}, \mathrm{mm}$ & 18.56 & 23.22 \\
\hline Length of confuser $\mathrm{l}_{\mathrm{c}}, \mathrm{mm}$ & 18.56 & 23.22 \\
\hline Length of diffusor $\mathrm{l}_{\mathrm{d}}, \mathrm{mm}$ & 61.86 & 77.39 \\
\hline $\begin{array}{l}\text { Length of nose section of } \\
\text { mixer } \mathrm{n}_{\mathrm{ns}}, \mathrm{mm}\end{array}$ & 30.93 & 38.69 \\
\hline $\begin{array}{l}\text { The area of radiating surface of } \\
\text { nozzle Fr, m }\end{array}$ & 0.06 & 0.09 \\
\hline Amount of tiles, pcs & 16 & 25 \\
\hline Diameter of hole in tile, mm & 0.11 & 0.16 \\
\hline Amount of holes in tile, pcs & 2.0 \\
\hline Air-gas velocity, Wmix, m/s & 574 \\
\hline
\end{tabular}

Fig. 3 presents the optimal layout of a new gas burner device with dimensions of its main constituent elements.

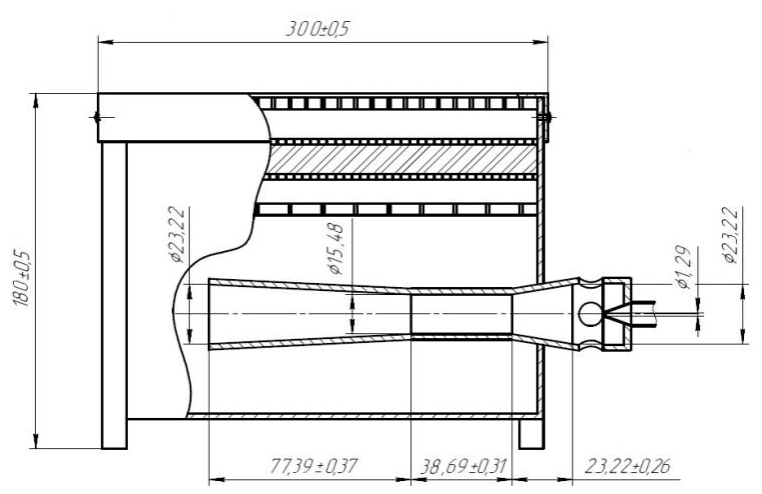

Fig. 3. Layout of a new gas burner with a heating capacity of $3.9 \mathrm{~kW}$.

When developing a technical solution aimed at ensuring a proportional distribution of mixture at the outlet of the burner device, a three-dimensional model of the injection part of the burner was built. Geometry was developed in Autodesk Inventor graphic CAD system, which allows exporting geometry to ANSYS CFX.

Color maps of distributions of pressure and velocity in the calculated geometry are shown in Fig. 4. The simulation results show that the highest velocity is in the nose section. A further increase in the number of iterations does not affect the numerical calculation.

It should be noted that the burner has a symmetrical velocity profile resulting in a uniform temperature 


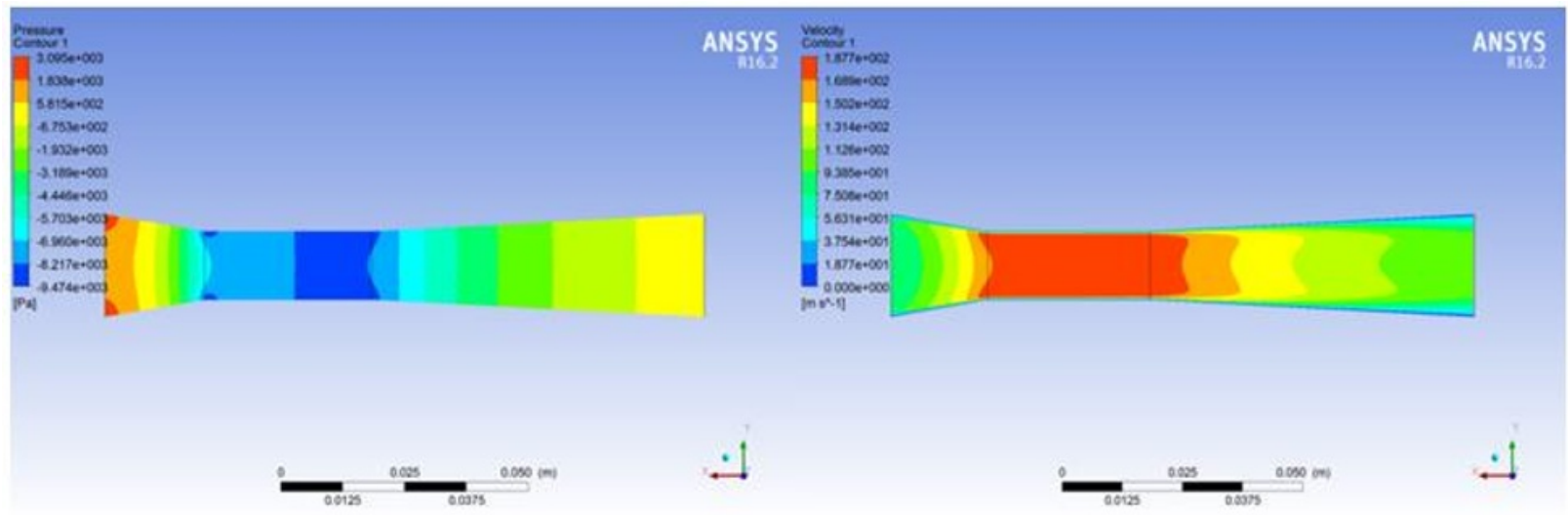

Fig. 4. Distribution of pressure (left) and velocity (right) of the air-gas mixture in the injection part of the burner in the ANSYS program.

profile. There is no explicit recirculation zone, which reduces hydraulic pressure losses. As it can be seen from figures, the design has a sufficiently high completeness of combustion and low velocities, due to which the temperature and concentration of nitrogen oxides at the outlet of burner device are reduced.

Three-dimensional modeling in the ANSYS CFX software package allowed developing technical solutions related to modernization and selection of optimal design of burners for domestic and power boilers.

\section{Conclusions}

The following results were obtained from the computational and experimental studies:

- The relevance of the use of gas burner devices is specified, the operation principle of such devices is described, and a review of manufacturers and patented technologies is carried out;

- Based on the review results, a comparison of devices was made, their advantages and disadvantages were identified, as well as the prospects of design;

- The concept of a new gas burner device was developed, which doesn't have the identified disadvantages of the existing devices;

- A new model of gas burner device was developed;

- A structural analysis was performed, which allowed us to determine the geometric parameters of the device;

- The injection part of burner was simulated in the ANSYS software according to the developed design.

It was found that infrared radiation from a heated surface of radiation burner nozzle provides intensive heat transfer in furnaces and boilers, their high efficiency at low flue gas temperatures, and very low NOx emission. Effective gas combustion is facilitated by additional heating of initial fuel mixture during filtration through the hot walls of the porous nozzle. The design of radiation burner has high operational properties, provides effective combustion of gaseous fuels up to $99 \%$ and meets the highest environmental standards and requirements. The burner was numerically simulated and appropriate presentations of physical processes were obtained.

\section{References}

[1] L.V. Larchenko, R.A. Kolesnikov, L. Mukhametova, Russian oil and gas industry as a sphere of international interests and economic cooperation, E3S Web of Conferences 161, 01006 (2020).

[2] N. Politaeva, Y. Smyatskaya, R. Al Afif, C. Pfeifer, L. Mukhametova, Development of FullCycle Utilization of Chlorella sorokiniana Microalgae Biomass for Environmental and Food Purposes, Energies 13, 10, 2648 (2020).

[3] V. Markov, A. Fedyukhin, I. Sultanguzin, B.G. Matisov, N.V. Nikitkov, V.V. Izrantsev, V.G. Knorring, G.A. Konrashkova, L.R. Mukhametova, Improvement of energy efficiency of motor fuel production at oil refinery, IOP Conference Series: Earth and Environmental Science 337, 1, 012080 (2019).

[4] I.A. Sultanguzin, E.V. Zhigulina, Y.V. Yavorovsky, I.D. Kalyakin, A.V. Govorin, A.V. Fedyukhin, A.A. Krolin, S.V. Guzhov, O. Derevianko, L. Mukhametova, Development strategy of the energy supply system for MPEI campus blocks based on green building, IOP Conference Series: Earth and Environmental Science 288, 1, 012071 (2019).

[5] E. Sukhareva, A. Fedyukhin, O. Derevianko, M. Egorov, L. Mukhametova, I. Akhmetova, Optimization of combined heat and power plant operating mode by means of underutilized equipment mothball, IOP Conference Series: Earth and Environmental Science 288, 1, 012122 (2019).

[6] S.E. Najim, A.C. Styles, N. Syred, Flame movement mechanisms and characteristics of gas fired cyclone combustors, Eighteen Symposium (International) on Combustion 18, 1, 1949-1957 (1981).

[7] Nanjia Yu, Bo Zhao, Gonghan Li, Jue Wang, Experimental and simulation study of a Gaseous 
oxygen, Gaseous hydrogen vortex cooling thrust chamber, Acta Astronautica 118, 11-20 (2016).

[8] A.A. Sinitsyn, L. Mukhametova, Practical applicability of the method for measuring pressure of controlled medium on the example of a pulsating combustion boiler, IOP Conference Series: Earth and Environmental Science Proceedings of the Conference the international scientific conference Efficient waste treatment 2018, EWT-2018, 012063 (2019).

[9] A.A. Sinitsyn, D. Rusakov. V.V. Izrantsev, S.A. Kravchenko, G.A. Konrashkova. Investigation of gas fuel combustion efficiency at magnetic field treatment, IOP Conference Series: Earth and Environmental Science Proceedings of the Conference the international scientific conference Efficient waste treatment - 2018, EWT-2018, 012082 (2019).

[10] A.N. Naimov, A.A. Sinitsyn A., F. Gazizov, A.P. Eperin, Yu.A. Rundygin, G.A. Agasiants, S.M. Galileev, T.R. Akhmetov, Mathematical modeling of heating temperature mode for a heat exchange system of the type «pipe in pipe», IOP Conference Series: Earth and Environmental Science Proceedings of the Conference the international scientific conference Efficient waste treatment - 2018, EWT-2018, 012068 (2019).

[11] A.A. Sinitsyn, Device for radiation-convective heating of working bodies, Patent of the Russian Federation, 129608, 27.06.2013, application no. 2012141775/06 dated 01.10.2012.

[12] D.A. Belyanskiy, A.A. Sinitsyn, A device for controlling the temperature of the working fluid, Patent of the Russian Federation, 119877 RU, Int. Cl.7 G01K 7/00, EnergoExpert LLC, pub. 27.08.2012.

[13] V.M. Shmelev, A.D. Margolin, Radiation burner, Patent of the Russian Federation, 2151957, MPK F23D14/12, declared 03.03.1999, publ. 27.06.2000.

[14] V.K. Baev, A.V. Potapkin, A.I. Trubitsin, Gas flameless burner, Patent of the Russian Federation, 2137040, MPK F23D14/14, declared 03.10.1998, dated 10.09.1999.

[15] A.F. Gekov, N.M. Lipovyi, A.N. Popov, F.N. Smus, B.E. Farfel, Radiation burner, Patent of the Russian Federation, 2094703, MPK F23D14/12, declared 18.06.1996, dated 27.10.1997.

[16] A.A. Sinitsyn, N.N. Boytsova, I.G. Akhmetova, S.O. Makoev, A. Asadpoori, O.A.Stepanov, N.V. Rydalina, E.O. Antonova, B.G.Aksenov, Study of operation of power-generating devices of gaseous fuels combustion, International Journal of Mechanical Engineering and Technology 10, 2, 1480-1490 (2019).

[17] A.A. Sinitsyn, Simulation of fire engineering processes in energy devices aimed at their optimization and improvement of reliability (Life Science Journal, the Acta Zhengzhou University
Oversea Version, Marsland Press: New York, 10, 2013)

[18] L.S. Berezina, A.A. Sinitsyn, To the development of a new burner device of a combined type, XII Annual scientific session of graduate students and young scientists: Materials of the interregional scientific conference: in 2 volumes, V. 1: Naturaltechnical direction (Vologda: VoGU, 258-260, 2018). 